\title{
EMISSIONS OF NON-METHANE ORGANIC COMPOUNDS FROM A GRASSLAND SITE
}

\author{
Yoshiko Fukui and Paul V. Doskey \\ Environmental Research Division \\ Argonne National Laboratory \\ Argonne, IL. 60439
}

RECEIVED

FEB 281996

OSTI

\section{DISCLAIMER}

This report was prepared as an account of work sponsored by an agency of the United States Government. Neither the United States Government nor any agency thereof, nor any of their employees, makes any warranty, express or implied, or assumes any legal liability or responsibility for the accuracy, completeness, or usefulness of any information, apparatus, product, or process disclosed, or represents that its use would not infringe privately owned rights. Reference herein to any specific commercial product, process, or service by trade name, trademark, manufacturer, or otherwise does not necessarily constitute or imply its endorsement, recommendation, or favoring by the United States Government or any agency thereof. The views and opinions of authors expressed herein do not necessarily state or reflect those of the United States Government or any agency thereof.

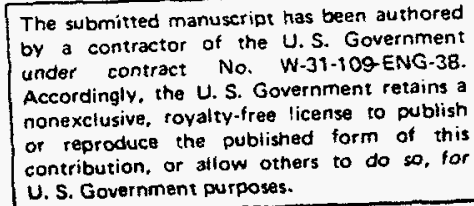
by a contractor of the U.S. Government under contract No. W-3i-109ENG-38.
Accordingly. the U.S. Government retains a nonexclusive, toyalty-free license to publish or reproduce the published form of this or repradico ar allow others to do so, for U. S. Government purposes.

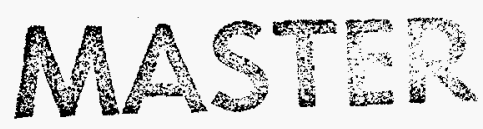




\section{DISCLAMMER}

Portions of this document may be illegible in electronic image products. Images are produced from the best available original document. 


\title{
EMISSIONS OF NON-METHANE ORGANIC COMPOUNDS FROM A GRASSLAND SITE
}

\author{
Yoshiko Fukui and Paul V. Doskey \\ Environmental Research Division, Argonne National Laboratory
}

Abstract. A mixture of oxygenated hydrocarbons (OxHCs), isoprene, and monoterpenes was detected in the emissions from a grassland site in the midwestern United States. A plot dominated by crown vetch (Coronilla varia) and bluegrass (Poa spp.), exhibited a constant decrease in emissions of total non-methane organic compounds (NMOCs) from $580 \mu \mathrm{g} \mathrm{m}^{-2} \mathrm{hr}^{-1}$ in June 1992 to $150 \mu \mathrm{g} \mathrm{m}^{-2} \mathrm{hr}^{-1}$ in October 1992, except for a slight increase in August. Oxygenated hydrocarbons (methanol, acetaldehyde, and acetone) and terpenes (isoprene, limonene, myrcene, $\alpha$-pinene, and $\beta$-pinene) composed about $90 \%$ and $10 \%$ of the identified NMOC emissions, respectively. Isoprene represented about $10 \%$ of the terpene emissions. Total NMOC emission rates based on vegetative biomass averaged $2.3 \mu \mathrm{g} \mathrm{g}^{-1} \mathrm{hr}^{-1}$, with $10 \%$ of the identified NMOCs attributed to monoterpenes and the remainder mainly OxHCs. Over the course of the investigation, the relationship between the monoterpene emission rate and the temperature for a single plot was logarithmic and similar to the one between compound vapor pressure and temperature. However, emission rates normalized to temperature decreased throughout the summer and fall, indicating that parameterizations of emission rates from herbaceous plants must include a factor to compensate for environmental conditions such as soil moisture and nutrient deposition, which affect plant phenology and the seasonal pattern of species dominance.

\section{Introduction}

Non-methane organic compounds (NMOCs) play an important role in the photochemical production of ozone in both urban and rural atmospheres [Lurman et al., 1983; Trainer et al., 1987; Chameides et al., 1988; Cardelino and Chameides, 1990; Fehsenfeld et al., 1992]. Biogenic sources account for about $90 \%$ of the global emissions of NMOCs, 
with the major fraction derived from terrestrial vegetation [Zimmerman et al., 1978]. Emissions from deciduous and coniferous trees and agricultural crops have been investigated in both laboratory and field studies [Tingey, 1981; Isidorov et al., 1985; Lamb et al., 1985; Juuti et al., 1990; Guenther et al., 1991; Winer et al., 1992]. A compilation of data by Lamb et al. [1987] indicates that emission rates from deciduous and coniferous trees are greater by an order of magnitude than those for other types of vegetation. However, very little information exists on the identity and quantity of emissions from grassland vegetation.

The objective of this investigation was to determine the seasonal variation of NMOC emissions from a grassland ecosystem [Fukui, 1994]. Emissions were measured via an enclosure technique and collected in Summa ${ }^{\circledR}$ passivated stainless steel canisters. The samples were analyzed by cryogenic preconcentration/high-resolution gas chromatography for several classes of organic compounds including alkanes, alkenes, aromatics, terpenes, alcohols, aldehydes, and ketones. Seasonal variations in the type of NMOCs emitted from a grassland site and a quantitative assessment of the emission rates are presented.

\section{Sampling and Analysis}

The site of the investigation was the Argonne meteorological monitoring site in the southwest corner of Argonne National Laboratory, Argonne, Illinois. The study area contained a mixture of short, wild grasses and broadleaf plants about $10-40 \mathrm{~cm}$ high. Species common to the site included bluegrass (Poa spp.), yellow foxtail (Setaria lutescens), quackgrass (Agropyron repens), horse nettle (Solanum carolinense), and crown vetch (Coronilla varia).

Samples were collected via a closed-chamber technique with a rigid, semi-transparent polycarbonate chamber (United States Plastic Corp., Lima, OH). About $80 \%$ of the visible light energy from a cloudless sky was transmitted through the chamber. The internal dimensions of the chamber were $60 \mathrm{~cm}(\mathrm{~L}) \times 40 \mathrm{~cm}$ (W) $\times 37.5 \mathrm{~cm}(\mathrm{H})$. The sides were slightly tapered, so that the internal volume was $84.5 \mathrm{~L}$. A rectangular polymethyl 
methacrylate frame $(64 \mathrm{~cm} \times 44 \mathrm{~cm})$ with a trough $5 \mathrm{~cm}$ (W) $\times 3.5 \mathrm{~cm}$ (D) was made to fit the chamber. The inner edge of the frame was $12.5 \mathrm{~cm}$ deep. Two weeks before sampling, a rectangle was cut into the ground, and the frame was inserted and backfilled with dirt to minimize the flow of ambient air into the chamber (Figure 1). The air within the chamber was isolated from the ambient air by placing the chamber in a trough filled with water. For sites where biomass-based emission rates were determined, all vegetation covered by the chamber was clipped at a height of about $1 \mathrm{~cm}$ above the ground, sorted by species, dried at $65^{\circ} \mathrm{C}$ to constant weight, and weighed. The frame was then moved to another site. To observe temporal variations of the emission rate from a single site, another frame was permanently installed on the ground, and the vegetation within it remained undisturbed for the duration of the investigation.

Air within the chamber was sampled from an upper corner through gas chromatographic grade stainless steel tubing $(40 \mathrm{~cm} \times 0.635 \mathrm{~cm}$ i.d.) as shown in Figure 1 . Samples were collected in 6-L Summa ${ }^{\circledR}$ passivated stainless steel canisters (Scientific Instrumentation Specialists, Moscow, ID). Temperatures of the ambient and chamber air were monitored during sample collection. Emission rates were calculated from the concentrations of NMOCs in ambient air and the chamber air for separate covering periods of $10 \mathrm{sec}, 1 \mathrm{~min}$, $3 \mathrm{~min}$, and $5 \mathrm{~min}$ by using linear regression analysis. Between emission measurements, the chamber was removed, and the surface was allowed to equilibrate for 5 min to so that the temperature returned to ambient levels. Emission rates were based on either the covered surface area or the harvested plant biomass. Samples were collected every 2-3 weeks at noon and were analyzed immediately.

The canister cleaning and analysis techniques have been described elsewhere [Doskey et al., 1991]. Briefly, the samples were analyzed with a Chemical Data Systems model 330 (CDS 330) sample concentrator (Autoclave Inc., Oxford, PA), which was interfaced to a Hewlett Packard (HP) 5890A high-resolution gas chromatograph (HRGC) with flame ionization detector (FID). We typically preconcentrated sample volumes of $250 \mathrm{~mL}$ or less for 
analysis because water in larger samples extinguished the flame in the FID. NMOCs were quantified with National Institute of Standards and Technology (NIST) standard SRM 1665b, containing $2.87 \pm 0.03 \mathrm{ppm}$ propane in air. The hydrocarbons were identified by comparing retention times of standards prepared in static dilution bottles with samples injected under identical chromatographic conditions. To derive the total NMOC concentration, the FID response of the identified oxygenated hydrocarbons (OxHCs) was subtracted from the total FID response. Except for the $\mathrm{C}_{2}$ non-methane hydrocarbons (NMHCs) ethene, acetylene, and ethane, which were not quantified because they could not be resolved from methane, this difference was operationally defined as the total NMHCs. The total NMHC concentration, calculated by using the response of the propane standard, was converted from $\mathrm{ppbC}$ to $\mathrm{ppb}$ by assuming that the average molecular weight and number of carbon atoms were $100 \mathrm{~g} \mathrm{~mole}^{-1}$ and 6 , respectively. The $\mathrm{OxHC}$ responses were corrected by using effective carbon numbers as suggested by Jorgensen et al. [1990] and Scanlon and Willis [1985] to compensate for their diminished response in the FID. The total NMOC concentration was operationally defined as the sum of the identified OxHCs and the total NMHCs. The combined analytical error for concentration measurements via this technique is about $\pm 5 \%$ for NMHCs and about $\pm 10 \%$ for OxHCs. Average correlation coefficients and standard errors (in parentheses) for the measurements of the alkane, aromatic, OxHC, terpene, and total NMOC emission rates were $0.41(> \pm 100 \%), 0.64( \pm 40 \%), 0.82( \pm 20 \%), 0.82( \pm 25 \%)$, and $0.84( \pm 30 \%)$, respectively.

\section{Results and Discussion}

The NMOCs in the chamber air included a mixture of OxHCs, isoprene, monoterpenes, alkanes, and aromatics. OxHCs such as methanol, ethanol, acetaldehyde, and acetone were present in the highest concentrations. Isoprene and the monoterpenes limonene, myrcene, and $\alpha$ - and $\beta$-pinene were present in lower concentrations than the oxygenates. Lesser amounts of alkanes (propane, 2-methylpropane, n-butane, 2-methylbutane, and n-pentane) and aromatics (benzene, toluene) were found. The mixture of hydrocarbons observed at our grassland site 
was similar to the mixture found in forested regions of the southeastern United States [Fehsenfeld et al., 1992].

We determined the covering period during which the NMOC emission rate would be constant by measuring the concentrations of hydrocarbons in the chamber for several different covering periods in full sunlight. The temperature inside the chamber typically increased at a rate of approximately $1-2^{\circ} \mathrm{C} \mathrm{min}^{-1}$, and water vapor generated during plant transpiration condensed on the chamber walls within about 1-3 min, depending on the amount of covered biomass. The emission rates for methanol, isoprene, and myrcene on 22 June 1992 for covering periods up to $1 \mathrm{~min}$ in length were $26,2.5$, and $5.4 \mathrm{ppbC} \min ^{-1}$, respectively. Emissions then decreased but remained constant at rates of 7.8, 0.12, and $1.5 \mathrm{ppbC} \mathrm{min}^{-1}$ for covering periods up to $7 \mathrm{~min}$ long (Figure 2). The declining emission rates were apparently caused by stresses imposed on the plants by the enclosure or, for the more soluble oxygenates, by absorption in the condensed water on the chamber walls. For measurements in which the emission rate declined for covering periods greater than $1 \mathrm{~min}$, we used the concentrations of the NMOCs in the ambient air and in the chamber air during the 10-sec and 1-min covering periods to derive the emission rate. Measurements of monoterpene emissions from various species of plants have indicated that the emission rate can be modeled after the logarithmic relationship between temperature and compound vapor pressure [Tingey et al., 1991; Guenther et al., 1993]. We were concerned that the increase in monoterpene concentration we observed was related solely to the increase in temperature of the chamber air. However, the increase in monoterpene concentration was linear and not logarithmic.

We were also concerned with the effect of light on emission measurements. Vegetation exposed to a variably cloudy sky exhibited rates of methanol, isoprene, and myrcene emissions that decreased from 100, 3.8 and $19 \mu \mathrm{g} \mathrm{m}^{-2} \mathrm{hr}^{-1}$, respectively, under a clear sky to $49,0.94$, and $10 \mu \mathrm{g} \mathrm{m}^{-2} \mathrm{hr}^{-1}$, respectively, when a cloud came overhead. The temperature of the chamber air increased by $6.5^{\circ} \mathrm{C}$ under clear skies within the 3-min measurement period but only by $0.5^{\circ} \mathrm{C}$ when the cloud was overhead. MacDonald and Fall [1993] found a direct 
correlation between methanol emissions from plants and stomatal conductance. Light is also necessary for the emission of isoprene from vegetation, and algorithms describing its influence have been reported [Guenther et al., 1993]. Light has an insignificant effect on monoterpene emissions in comparison to temperature, but light indirectly affects emissions through its control of the monoterpene pool size [Tingey et al., 1991]. We decided to limit our measurements to clear-sky conditions because changes in the flux of radiation created temperature fluctuations in the chamber, and the effect of light on NMOC emissions from the plant species in our investigation was unclear.

We measured the emissions of NMOCs for an undisturbed plot containing predominantly crown vetch and bluegrass from 22 June 1992 through 22 October 1992 (Table 1). Data were collected when radiation levels were greater than $500 \mathrm{~W} \mathrm{~m}^{-2}$. The total NMOC emissions decreased almost linearly from $580 \mu \mathrm{g} \mathrm{m}^{-2} \mathrm{~h}^{-1}$ at the onset of summer to about $150 \mu \mathrm{g} \mathrm{m}^{-2} \mathrm{~h}^{-1}$ during fall, except for a slight increase in the emission rates during August. The majority of the emissions were OxHCs.

Trends in the seasonal emission profiles of the aromatics and alkanes were different from those of isoprene, the monoterpenes, and OxHCs (Table 1). Aromatic hydrocarbons were sorbed by the surface during all measurement periods. Similar results were obtained during a preliminary investigation at a different site in 1991. At that time our experiments demonstrated that declining concentrations of aromatics in the chamber air were not due to sorption by the polycarbonate chamber or the polymethyl methacrylate frame. Our results indicated that the atmosphere may be the source of the aromatic hydrocarbons observed in uncontaminated soil [Simonart and Batistic, 1966].

The emission profiles of the alkanes were dissimilar from those of the aromatics (Table 1). Some sampling periods had slight emissions of alkanes, while during others they were being deposited. However, the uncertainties in the alkane emission rates are large, as indicated by the very large standard errors $(> \pm 100 \%)$. The large uncertainties are caused by the similarity of the concentrations of $n$-alkanes in the ambient and chamber air. Results from 
investigations cited by Graedel [1979] indicated that light alkanes are emitted from grass. Kimmerer and Kozlowski [1982] found that ethane is emitted from plants under stress. The dissimilarity of the alkane and terpene emission profiles would argue against a vegetation source. Smith and Restall [1971] found that $\mathrm{n}$ - and $i$-butane are produced in soils. Isidorov [1990] reported that $\mathrm{C}_{1}-\mathrm{C}_{4}$ alkanes are among the final products of metabolism of anaerobic soil bacteria. Our data indicate that the flux of these compounds can also be into the soil. However, these nonpolar hydrocarbons are unlikely to be sorbed by the soil. Therefore, the exchange of these gases may be related to changes in pressure within the chamber during sampling, like the effects observed during measurements of the $\mathrm{N}_{2} \mathrm{O}$ flux from soils [Denmead, 1979]. These changes in pressure may also be responsible for the large uncertainties.

The bulk of emissions at our site were composed of OxHCs (Table 1). The similarity of the methanol and terpene emission profiles may indicate a common source. MacDonald and Fall [1993] identified methanol as an NMOC emission from several species of plants. Another source may be the microbial degradation of organic matter in soils. For example, methanophiles produce methanol during the aerobic oxidation of methane [Stainer et al., 1986]. Ethanol was also observed in our samples, but it could not be routinely separated from 2-methylbutane. Acetaldehyde emissions exhibited three maxima during our investigation, the most prominent during August. Maxima in acetone emissions preceded the largest acetaldehyde emissions, except for a period during June when the maxima coincided. Ethanol is produced during the fermentation of organic matter and could originate from either microbial activity in the soil or anaerobic respiration in vegetation. Fermented toxic products like ethanol and acetaldehyde are formed in roots of flooded plants, transported to aboveground portions of the plant, and removed in the transpiration stream [Chirkova, 1978]. Ethanol use in roots is known to form acetaldehyde initially and ultimately to produce acetone [Cossins, 1978]. Kimmerer and Kozlowski [1982] found enhanced emissions of ethanol and acetaldehyde from plants exposed to oxidizing pollutants (e.g., $\mathrm{SO}_{2}, \mathrm{O}_{3}$ ), water deficit, and freezing. Thus, 
these oxygenated hydrocarbons can apparently be emitted from plants in both flooded and dry soils.

Isoprene and monoterpene emissions were lower than those of the OxHCs (Table 1). The monoterpenes in highest concentration were limonene and myrcene, with lesser amounts of $\alpha$ - and $\beta$-pinene. Isoprene was about $10 \%$ of the terpene emissions. Winer et al. [1989] identified limonene and $\alpha$ - and $\beta$-pinene in emissions from annual grasslands in California. The trend in the emission of the monoterpenes at our site was very similar to that of methanol. Monoterpene emissions are believed to be controlled largely by changes in ambient temperature and are frequently modeled by using the relationship between the compound vapor pressure and temperature [Tingey et al., 1991; Guenther et al., 1993]. The relationships between the measured emission rates of limonene and myrcene, the calculated vapor pressures for the two compounds, and the measured ambient temperature for our study site are presented in Figure 3. The relationship between emission rate and temperature is logarithmic, like that between vapor pressure and temperature. Samples represented by the lowest ambient temperatures were collected in late summer and early fall, while the midrange and highest temperatures were recorded for samples collected during mid and early summer, respectively. The live standing crop of vegetation at this site declined throughout the growing season. Consequently, the slopes of the vapor pressure and emission rate curves would probably be similar if the emission rates were based on the weight of living phytomass rather than the covered surface area. Our results also indicate that the emission rates were greater than those predicted from vapor pressure alone. This phenomenon has been attributed to changes in the pathway conductance or monoterpene pool size in plants [Tingey et al., 1991].

We harvested the vegetation on five occasions to derive biomass-based emission rates. Methanol emission rates ranged from 0.46 to $2.0 \mu \mathrm{g} \mathrm{g}^{-1} \mathrm{hr}^{-1}$, below the average value of $13.2 \mu \mathrm{g} \mathrm{g}^{-1} \mathrm{hr}^{-1}$ measured by MacDonald and Fall [1993] for several species of plants. The monoterpene emission rate decreased from about $0.25 \mu \mathrm{g} \mathrm{g}^{-1} \mathrm{hr}^{-1}$ on 17 July 1992 to $0.015 \mu \mathrm{g} \mathrm{g}^{-1} \mathrm{hr}^{-1}$ by the end of September. During this time the live vegetation in the plots 
decreased from $90 \%$ to $68 \%$ of the total harvested biomass, but the mass of living bluegrass and crown vetch, the dominant species in the plots, remained fairly constant. A monoterpene emission rate of $0.034 \mu \mathrm{g} \mathrm{g}^{-1} \mathrm{hr}^{-1}$ was measured on 12 October 1992 for vegetation that had grown back in a plot exhibiting an emission rate of $0.25 \mu \mathrm{g} \mathrm{g}^{-1} \mathrm{hr}^{-1}$ on 17 July 1992. An emission measurement for similar vegetation in another plot on 29 September 1992 that had never been clipped was lower by a factor of 2 than the October measurement, even though the mass of both bluegrass and crown vetch were significantly lower during October.

To observe seasonal variations of the monoterpene emission rates, the emission rates of limonene and myrcene were normalized to $25^{\circ} \mathrm{C}$ by using the ratio of the vapor pressure at $25^{\circ} \mathrm{C}$ to the vapor pressure at ambient temperature (Figure 4). The normalized emission rates based on both area and biomass generally decreased from late June to October. It was expected that the slope of the line for emission rates based on area would be nearly zero if they were normalized to biomass because the weight of living biomass decreases throughout the growing season. Yokouchi et al. [1984] found that monoterpene emissions from Pinus densiflora during winter were lower than those expected on the basis of temperature alone, they attributed the difference to the effect of lower light intensities on the production of monoterpenes. Isidorov et al. [1985] found that monoterpene emissions for Populus balsamifera were highest in spring but had ceased by summer. Investigators have observed that the composition of the monoterpene pool in plants varies seasonally, but the effects on emission rates have not been investigated [Tingey et al., 1991]. Our data may indicate that the growth stage of the vegetation has a major effect on monoterpene emissions from herbaceous plants. Guenther et al. [1991] reported a trend toward decreasing monoterpene emissions with increasing age for eucalyptus leaves. The herbaceous plants in our investigation apparently exhibit a similar trend.

We measured an average total NMOC emission rate for perennial grasslands of about $2.3 \mu \mathrm{g} \mathrm{g}^{-1} \mathrm{hr}^{-1}$, with approximately $10 \%$ of the identified emissions composed of monoterpenes. The average temperature during the measurements was $24^{\circ} \mathrm{C}$, and the range 
was $17-29^{\circ} \mathrm{C}$. Winer et al. [1992] reported a total NMOC emission rate of $0.1 \mu \mathrm{g} \mathrm{g}^{-1} \mathrm{hr}^{-1}$ for annual grasslands in California. The average temperature during their measurements was $33^{\circ} \mathrm{C}$, with a range of $17-43^{\circ} \mathrm{C}$. Approximately $20 \%$ of the emissions from the California grasslands were monoterpenes. Lamb et al. [1987] reported average total NMOC emission rates of 25 and $12 \mathrm{\mu g} \mathrm{g}^{-1} \mathrm{hr}^{-1}$ (at $30^{\circ} \mathrm{C}$ ) for oak and pine trees, respectively, with 93 and $24 \%$ of the emissions for oak and pine composed of terpenes. Using biomass estimates for deciduous and coniferous trees in grassland regions from Lamb et al. [1987], we estimated the contributions of total NMOCs and terpenes from trees at $30^{\circ} \mathrm{C}$ to be 1800 and 1100 $\mu \mathrm{g} \mathrm{m}^{-2} \mathrm{hr}^{-1}$, respectively. Our estimates of total NMOC and terpene emission rates for grassland varieties of herbaceous plants in our undisturbed plot were $110-660 \mu \mathrm{g} \mathrm{m}^{-2} \mathrm{hr}^{-1}$ and $10-74 \mu \mathrm{g} \mathrm{m}^{-2} \mathrm{hr}^{-1}$, respectively. Herbaceous vegetation apparently is not a significant source of terpenes in grasslands. However, our measurements indicate that the contribution of oxygenated hydrocarbon emissions from herbaceous vegetation may be significant. Interestingly, ambient air samples collected in forests of the southeastern United States [Fehsenfeld et al., 1992] contained many of the same OxHCs that we identified as emissions from a grassland in the Midwest. Additional study is needed to identify and quantify the emissions of OxHCs from forested regions.

The half-lives of the OxHCs identified in this investigation with respect to oxidation by $\mathrm{OH}$ (except for acetaldehyde), are relatively long compared to those of the terpenes [Warneck, 1987]. However, these low reactivities will facilitate long-range transport of the OxHCs and subsequent formation of ozone in remote regions. To improve the predictive capability of tropospheric chemistry models, accurate emission inventories of NMOCs must be assembled. These inventories must also include OxHC emissions from biogenic sources.

\section{Conclusions}

The total NMOC emission rate for a plot dominated by bluegrass and crown vetch decreased rather consistently from $580 \mu \mathrm{g} \mathrm{m}^{-2} \mathrm{yr}^{-1}$ in early summer to $150 \mu \mathrm{g} \mathrm{m}^{-2} \mathrm{yr}^{-1}$ 
during fall, with a minor increase during August. Terpenes and OxHCs contributed about 10 and $90 \%$ of the identified NMOC emissions, respectively. Terpene emissions consisted mainly of isoprene, limonene, myrcene, and $\alpha$ - and $\beta$-pinene. OxHCs included methanol, ethanol, acetaldehyde, and acetone. In addition to vegetation, microbial oxidation of organic matter in soils may produce methanol. Emissions of ethanol, acetaldehyde, and acetone may be related to anaerobic respiration in plants. The source of the isoprene and monoterpenes appears to be herbaceous vegetation. The monoterpene emission rates followed a logarithmic relationship with temperature, like the one between compound vapor pressure and temperature. Monoterpene emission rates normalized to temperature and based upon both area and biomass decreased throughout the growing season. Comparison of measured emissions from a newgrowth plot during fall with those from an old-growth plot during late summer indicated that the emission rate may vary with plant growth stage. Consequently, factors that take into account the temporal variations of environmental conditions like soil moisture and nutrient deposition as they affect plant phenology and the seasonal pattern of species dominance must also be included in parameterizations of emission rates of NMOCs from vegetation.

Acknowledgments. We thank Julie Jastrow for her assistance in identifying the vegetation at the study site. This work was supported by the U.S. Department of Energy under Contract No. W-31-109-ENG-38, as part of the Atmospheric Chemistry Program (ACP) of the Office of Energy Research, Office of Health and Environmental Research. 


\section{References}

Cardelino, C. A., and W. L. Chameides, Natural hydrocarbons, urbanization, and urban ozone, J. Geophys. Res., 25, 13971-13979, 1990.

Chameides, W. L., R. W. Lindsay, J. Richardson, and C. S. Kiang, The role of biogenic hydrocarbons in urban photochemical smog: Atlanta as a case study, Science, 241, 1473-1475, 1988.

Chirkova, T. V., Some regulatory mechanisms of plant adaptation to temporal anaerobiosis, in Plant Life in Anaerobic Environments, edited by D. D. Hook and R. M. M. Crawford, pp. 137-154, Ann Arbor Science, Ann Arbor, 1978.

Cossins, E. A., Ethanol metabolism in plants, in Plant Life in Anaerobic Environments, edited by D. D. Hook and R. M. M. Crawford, pp.169-202, Ann Arbor Science, Ann Arbor, 1978.

Denmead, O. T., Chamber systems for measuring nitrous oxide emission from soils in the field, Soil Sci. Soc. Am. J., 43, 89-95, 1979.

Doskey, P. V., The effect of treating air samples with magnesium perchlorate for water removal during analysis for non-methane hydrocarbons, $\underline{\mathrm{HRC}}, \underline{14}, 724-728,1991$.

Fehsenfeld, F., J. Calvert, R. Fall, P. Goldan, A. B. Guenther, C. N. Hewitt, B. Lamb, S. Liu, M. Trainer, H. Westberg, and P. Zimmerman, Emissions of volatile organic compounds from vegetation and the implications for atmospheric chemistry, Global Biogeochem. Cycles, 6, 389-430, 1992.

Fukui, Y, Measurements of biogenic non-methane organic compound emissions from grasslands, Ph.D. Thesis, 200 pp., University of Illinois, Chicago, May 1994.

Graedel, T. E., Terpenoids in the atmosphere, Rev. Geophys. Space Phys., 17, 937-947, 1979.

Guenther, A. B., R. K. Monson, and R. Fall, Isoprene and monoterpene emission rate variability: Observations with eucalyptus and emission rate algorithm development, L.Geophys. Res., 26, 10799-10808, 1991. 
Guenther, A. B., P. R. Zimmerman, P. C. Harley, R. K. Monson, and R. Fall, Isoprene and monoterpene emission rate variability: Model evaluations and sensitivity analyses, L. Geophys. Res., 98, 12609-12617, 1993.

Isidorov, V. A., I. G. Zenkevich, and B. V. Ioffe, Volatile organic compounds in the atmosphere of forests, Atmos. Environ., 19, 1-8, 1985.

Isodorov, V. A., Organic Chemistry of the Earth's Atmosphere, 215 pp., Springer-Verlag, Berlin, 1990.

Jorgensen, A. D., K. C. Picel, and V. C. Stamoudis, Prediction of gas chromatography flame ionization detector response factors from molecular structures, Anal. Chem., 62 , 683-689, 1990.

Juuti, S., J. Arey, and R. Atkinson, Monoterpene emission rate measurements from a Monterey pine, J. Geophys. Res., 25, 7515-7519, 1990.

Kimmerer T. W. and T. T. Kozlowski, Ethylene, ethane, acetaldehyde, and ethanol production by plants under stress, Plant Physiol., 69, 840-847, 1982.

Lamb, B., H. Westberg, G. Allwine, and T. Quarles, Biogenic hydrocarbon emissions from deciduous and coniferous trees in the United States, J. Geophys. Res., 20, 2380-2390, 1985.

Lamb, B., A. Guenther, D. Gay, and H. Westberg, A national inventory of biogenic hydrocarbon emissions, Atmos. Environ., 21, 1695-1705, 1987.

Lurmann, F. W., A. C. Lloyd, and B. Nitta, Modeling potential ozone impacts from natural hydrocarbons-II. Hypothetical biogenic HC emission scenario modeling, Atmos. Environ., 17, 1951-1963, 1983.

MacDonald, R. C., and R. Fall, Detection of substantial emissions of methanol from plants to the atmosphere, Atmos. Environ., 27A, 1709-1713, 1993.

Scanlon, J. T. and D. E. Willis, Calculation of flame ionization detector relative response factors using the effective carbon number concept, J. Chrom. Sci., 23, 333-340, 1985.

Simonart, P. and L. Batistic, Aromatic hydrocarbons in soil, Nature, 212, 1461-1462, 1966. 
Smith, K. A. and S. W. F. Restall, The occurrence of ethylene in anaerobic soil, J. Soil Sci, $\underline{22}, 430-443,1971$.

Stainer, R. Y., J. L. Ingraham, J. L. Wheelis, and P. R. Painter, The Microbial World, 689 pp., Prentice-Hall, Englewood Cliffs, 1986.

Tingey, D. T., The effect of environmental factors on the emission of biogenic hydrocarbons from live oak and slash pine, in Atmospheric Biogenic Hydrocarbons Vol. 1 Emissions, edited by J. J. Bufalini and R. R. Arnts, pp. 53-72, Ann Arbor Science, Ann Arbor, 1981.

Tingey, D. T., D. P. Turner, and J. A. Weber, Factors controlling the emissions of monoterpenes and other volatile organic compounds, in Trace Gas Emissions by Plants, edited by T. D. Sharkey, E. A. Holland, and H. A. Mooney, pp. 93-119, Academic Press, Inc., San Diego, 1991.

Trainer, M., E. J. Williams, D. D. Parrish, M. P. Buhr, E. J. Allwine, H. H. Westberg, F. C. Fehsenfeld, and S. C. Liu, Models and observations of the impact of natural hydrocarbons on rural ozone, Nature, 329, 705-707, 1987.

Warneck, P, Chemistry of the Natural Atmosphere, Academic Press, Inc., San Diego, 1987.

Winer, A. M., J. Arey, S. M. Aschmann, R. Atkinson, W. D. Long, C. L. Morrison, and D. M. Olszyk, Hydrocarbon Emissions from Vegetation Found in California's Central Valley, A732-155, California Air Resources Board, Sacramento, 1989.

Winer, A. M., J. Arey, R. Atkinson, S. M. Aschmann, W. D. Long, C. L. Morrison and D. M. Olszyk, Emission rates of organics from vegetation in California's Central Valley, Atmos. Environ., 26A, 2647-2659, 1992.

Yokouchi, Y., A. Hijikata, and Y. Ambe, Seasonal variation of monoterpene emission rate in a pine forest, Chemosphere, 13, 255-259, 1984.

Zimmerman, P. R., R. B. Chatfield, J. Fishman, P. J. Crutzen, and P. L. Hanst, Estimates on the production of $\mathrm{CO}$ and $\mathrm{H}_{2}$ from the oxidation of hydrocarbon emissions from vegetation, Geophys. Res. Lett, 5, 679-682, 1978. 
Table 1. Emission rates of hydrocarbons $\left(\mu \mathrm{g} \mathrm{m}^{-2} \mathrm{hr}^{-1}\right)$ from a grassland site.

Julian Day

\begin{tabular}{lccccccccc} 
& 173 & 189 & 217 & 231 & 243 & 257 & 265 & 278 & 295 \\
\hline Methanol & 120 & 360 & 150 & 180 & 120 & 91 & 75 & 87 & 89 \\
Acetaldehyde & 32 & -0.45 & 11 & 58 & 19 & 14 & 24 & 12 & 15 \\
Acetone & 28 & 11 & 53 & 30 & 18 & 27 & 7.4 & 17 & 14 \\
Isoprene & 1.7 & 3.1 & 4.4 & 3.8 & 1.2 & -0.88 & 1.1 & 0.86 & 0.80 \\
Monoterpenes $^{\mathrm{a}}$ & 18 & 71 & 16 & 27 & 11 & 12 & 2.8 & 9.0 & 14 \\
Alkanes $^{\mathrm{b}}$ & 10 & -6.0 & -7.9 & -13 & 4.4 & 3.7 & -1.9 & -8.9 & 10 \\
Aromatics $^{\mathrm{c}}$ & -0.32 & -0.97 & -8.5 & -3.1 & -0.74 & -1.9 & -1.4 & -8.4 & -4.3 \\
Total NMOCd & 580 & 560 & 660 & 470 & 300 & 190 & 160 & 110 & 190 \\
\hline
\end{tabular}

a $\sum$ limonene, myrcene, $\alpha$ - and $\beta$-pinene.

b $\sum$ propane, 2-methylpropane, $n$-butane, 2-methylbutane, n-pentane.

c $\sum$ benzene, toluene.

d Calculated from total FID response. 


\section{Figure Captions}

Fig. 1. Enclosure system with 6-L Summa ${ }^{\circledR}$ passivated stainless steel canister for sample collection.

Fig. 2. NMOC concentrations in enclosure for covering periods up to $7 \mathrm{~min}$ long.

Fig. 3. Relationships between ambient temperature, monoterpene emission rates, and vapor pressures for a single grassland plot.

Fig. 4. Seasonal variation of monoterpene emission rates, normalized to $25^{\circ} \mathrm{C}$ for a single grassland plot and five plots where the vegetation was harvested. 


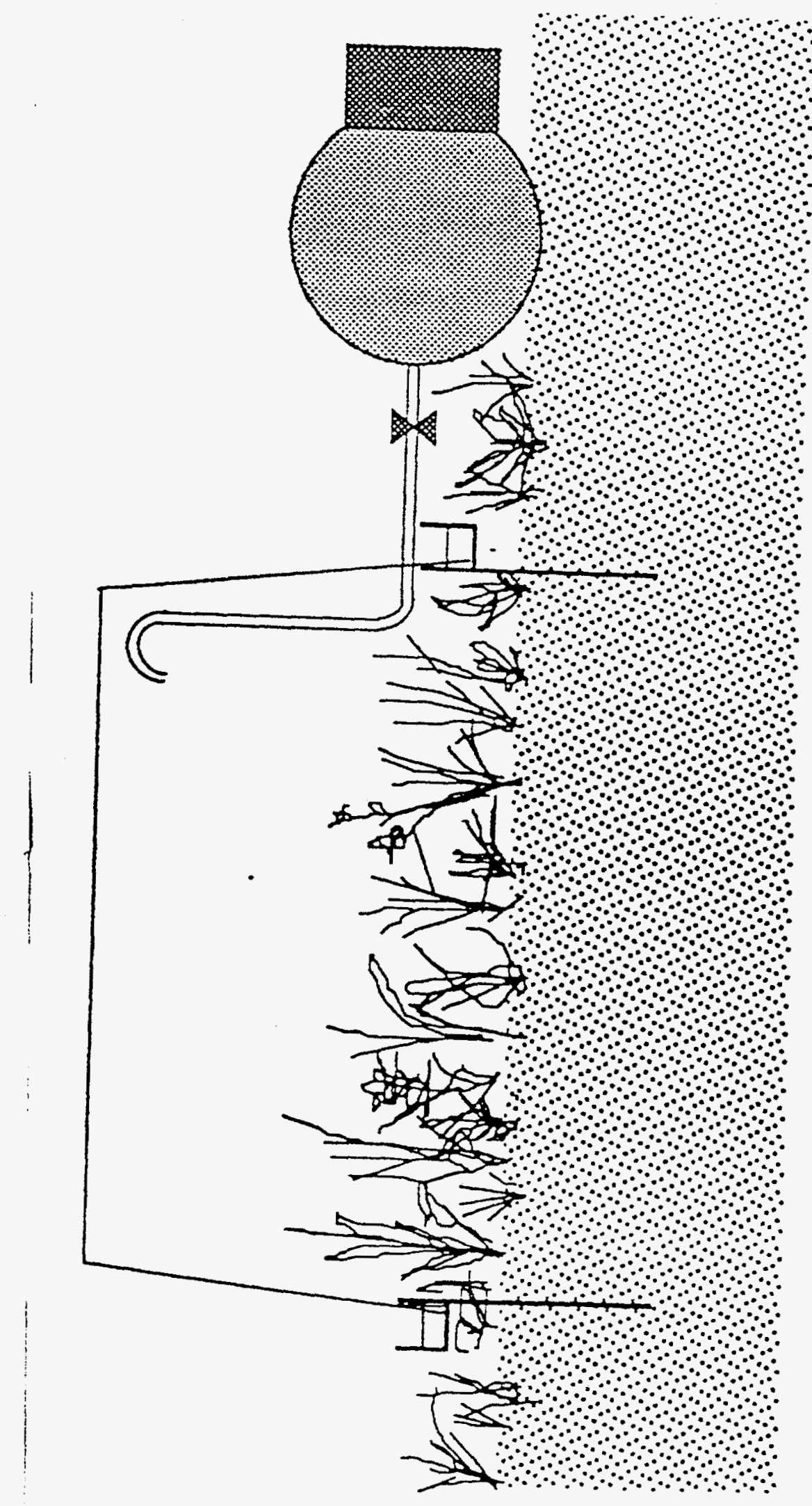


Isoprene, Myrcene

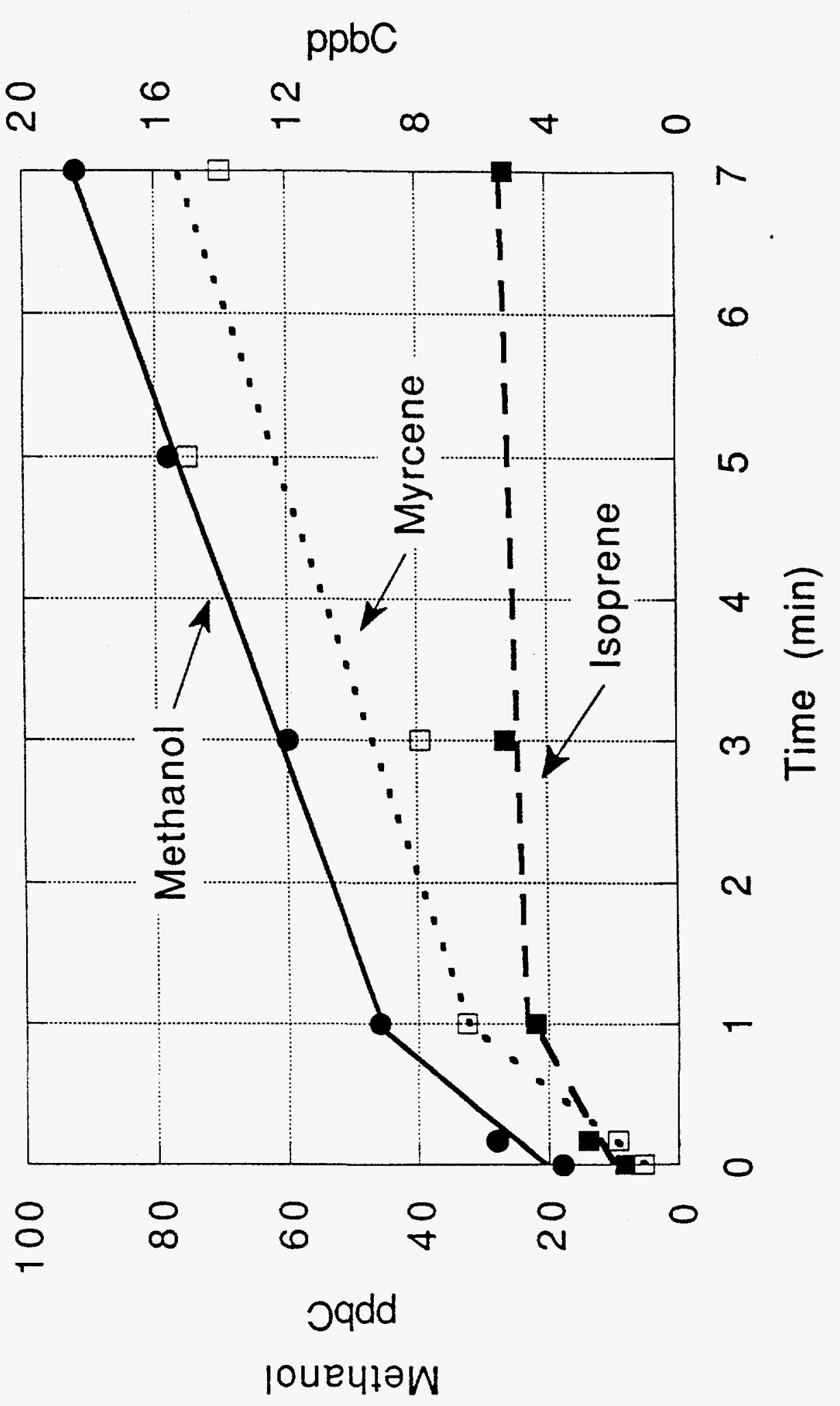




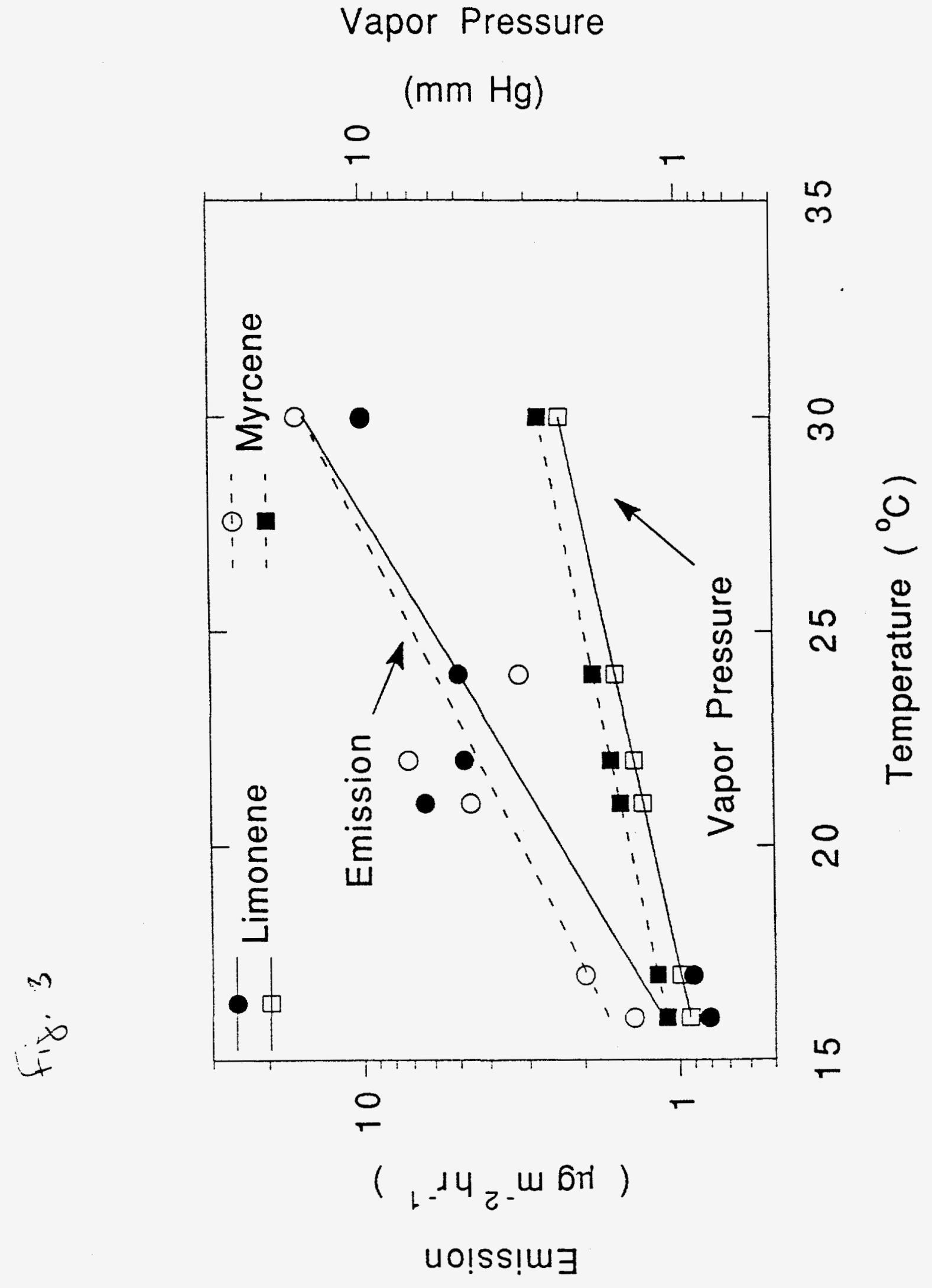

